7?

columns could find such input from a separate team useful. However, there are times when it could be handy to arrange a bit of extra support for patients whose illness has deteriorated, and for distressed people who are experiencing a psychological or social crisis. In those circumstances, busy clinicians will simply lower their threshold for the stated intention to admit to hospital and pull in nurses from the crisis team knowing that they will assist the patient in the community for a couple of weeks. Of course, this is not a rational way to use health service resources but it is an inevitable result of the diversion of staff to sub-specialist teams with such narrow and largely pointless clinical duties

The actual data obtained by Dibben et al will be useful in countering recent suggestions from crisis specialists that their services should be expanded to include older adults (Cooper et al, 2007).

Another letter commenting on this paper (Jha \& Boskovic, 2008, this issue) demonstrates that there are psychiatrists who are thinking very clearly about how best to provide effective, efficient and comprehensive mental healthcare to older people. I urge policy makers to seek advice on service models from the authors, Drs Jha and Boskovic, and other experienced old age psychiatry clinicians. They must not repeat the mistakes that have been made with services for working-age adults and foist unnecessary crisis resolution teams on older people with mental disorders.

COOPER, C., REGAN, C., TANDY, A. R., et al (2007) Acute mental health care for older people by crisis resolution teams in England. International Journal of Geriatric Psychiatry, 22, 263-265.

DIBBEN, C., SAHEED, H., KONSTANTINOS, S., et al (2008) Crisis resolution and home treatment teams for older people with mental illness. Psychiatric Bulletin, 32, 268-270.

JHA, A.\& BOSKOVIC,T. (2008) Crisis resolution and home treatment teams for older people (letter). Psychiatric Bulletin, 33,75.

Anthony J. Pelosi Consultant Psychiatrist, Hairmyres Hospital, East Kilbride G75 8RG, email: anthony.pelosi@nhs.net

doi: 10.1192/pb.33.2.75a

We thank Dr Pelosi for his interest in our study on the impact of a CRHTT for older people (Psychiatric Bulletin, November 2008, 32, 268-270). However, there is no misinterpretation of data, as suggested by Dr Pelosi. We tested chi-squared differences in the proportion of total number of admissions over number of crisis events and not total number of admissions per se.

We agree that it is possible, but far from definite, that some of the patients seen by the crisis team may have been sub-threshold for admission and we clearly stated this in our discussion: 'It may be argued that individuals who received home treatment only were below the "admission threshold" and the referrals to the CRHTT had been generated by the availability of this new service.' However by treating people early, one could argue that the CRHTT play an important role in preventing possible future admissions. As Dr Pelosi mentioned in his letter, crisis team support might 'come in handy' at the time of deterioration of illness, social or psychological crisis

The views of patients and carers are also important when developing new services. Our study showed that carers showed a trend towards greater satisfaction with the CRHTT compared with hospital admission. This is in keeping with a Cochrane review (Joy et al, 2006) which has shown that home treatment is a more satisfactory form of care for adults of working age with severe mental illness and their families. Cooper et al (2007) also make the point that home treatment may be important in maintaining the independence of the older person.

As responsible clinicians who take pride in our work we should always strive to offer the best evidence-based care and review our practice accordingly. We have suggested that a gold standard doubleblind randomised control trial needs to be done in older patients, including an economic evaluation. Nevertheless, our pragmatic study design shows that such a service may be helpful.

COOPER, C., REGAN, C., TANDY, A. R., et al (2007) Acute mental healthcare for older people by crisis resolution teams in England. International Journal of Geriatric Psychiatry, 22, 263-265.

JOY, C. B., ADAMS, C. E. \& RICE, K. (2006) Crisis intervention for people with severe mental illnesses. Cochrane Database of Systematic Review, 4, CD001087

Claire Dibben Specialist Registrar, Humera Saeed Specialist Registrar, Konstantinos Stagias Specialist Registrar (research post), Golam Mohammed Khandaker Specialist Registrar, *Judy S. Rubinsztein Consultant, Older Peoples Mental Health Services, Suffolk Mental Health Partnership NHS Trust, West Suffolk Hospital, Bury St Edmunds, Suffolk IP33 2QZ, email: judy. rubinsztein@smhp.nhs.uk

doi: 10.1192/pb.33.2.76

\section{NICE guidelines for epilepsy in learning disabilities service}

The National Institute for Health and Clinical Excellence (NICE) guidelines for epilepsy issued in October 2004 include special considerations for the care of women with epilepsy and people with learning disabilities.
We audited our practice with four guidelines:

1. Yearly structured reviews considering treatment effectiveness, tolerability, side-effects and adherence.

2. Risk assessment which includes bathing and showering, using electrical equipment, sudden unexpected death in epilepsy and managing prolonged or serial seizures.

3. To discuss the risk of higher mortality in people with epilepsy and learning disabilities with the individual, their family and/or carers.

4. Women with epilepsy and their partners must be given information and counselling about contraception conception, pregnancy and caring for children.

Data were collected by audit from both community and in-patient case notes. The first cycle, completed in October 2005 $(n=12)$, found that structured yearly reviews were done for $58 \%$ of the patients and risk assessment for 75\% (but did not include sudden unexpected death in epilepsy), but no advice was given to women $(0 \%$ of cases) and increased risk of mortality was not discussed $(0 \%$ of cases).

After raising the awareness within the team about NICE guidelines, the second cycle completed in September 2006 showed some improvement, with structured yearly review completed in $100 \%$ of cases, risk assessment in $75 \%$, and advice given to women in 50\%; however, increased risk of mortality was still not discussed (0\%)

A checklist for NICE guidelines has been included in medical notes and it was agreed within the team that if the risk of increased mortality was not discussed with patients or carers, it should be clearly documented with reasons.

*Neeraj Bajaj SpecialtyTrainee, Stobhill Hospital, 133 Balonrock Road, Glasgow G21 3UT, email: nbajaj@doctors.org.uk, Chandima Perera Specialist Registrar in Learning Disability, Edinburgh Rina Banerjee Consultant Learning Disability Psychiatrist, Stockton Learning Disability Services, Stockton

doi: 10.1192/pb.33.2.76a

\section{Taking the path less trodden: UK psychiatrists working in low- and middle-income countries}

The project run in Ghana by the South West London and St George's Mental Health National Health Service (NHS) Trust, Royal College of Psychiatrists and Challenges Worldwide, is a good model for developing opportunities for UK 
psychiatrists to practise in low- and middle-income countries (Psychiatric Bulletin, November 2008, 32, 431-435).

Higher specialist psychiatry trainees may spend 3 months in Ghana in psychiatry services as part of their training time. The aim is to provide a sustainable and continuing link between the UK and Ghana, based on development need, safety and Ghanaian population locally in south-west London.

We have been focusing on training the medical assistant level cadre in accordance with the general principles of development need and the wishes of our partners in Ghana. We have also focused on facilitating local improvement of ward systems.

We feel that this type of partnership is a good model for those interested in gaining overseas experience. We would recommend it to other health trusts in the $\mathrm{NHS}$ as a workable model of following through the Crisp report (2007). It ensures that the input of the trainee is sustainable, helpful and not an encumbrance on the local host.

There are instances of professionals setting up their own projects overseas in low- and middle-income countries. Although some projects work, many do not. It can be very difficult to sustain a project without a sufficient level of support and back-up.

\section{Acknowledgements}

We thank Dr Osei of Accra Psychiatric Hospital for hosting our trainees as well as Eoghan Mackie of Challenges
Worldwide. We acknowledge and thank the London Deanery and the South West London and St George's Mental Health NHS Trust for enabling this project to continue.

CRISP, N. (2007) Global Health Partnerships: the UK Contribution to Health in Developing Countries. Central Office of Information.

Peter Hughes Member of Board of International Affairs and Volunteers Sub-Committee, Royal College of Psychiatrists, and Consultant Psychiatrist Balham and Tooting CMHT, Old Estates Building, Springfield University Hospital, 61 Glenburnie Road, London SW17 7DJ, email: peter.hughes@swlstg-tr. nhs.uk

doi: 10.1192/pb.33.2.76b

\section{the college}

\section{Mentoring and coaching}

Occasional Paper OP66, November 2008, f10, $37 \mathrm{pp}$.

This paper on mentoring and coaching is a practical resource and reference guide. It is aimed at prospective mentees and mentors, with suggestions on training and preparation for these roles. Those involved in setting up mentoring schemes will find suggested approaches and templates for useful documents. The main body of the text includes 'capsules' of additional detailed information on specific topics and the appendices provide examples of useful publications and where to find further information. The guide covers both mentoring and coaching; most models of mentoring and coaching share the same basic premise, namely that the mentee is resourceful and that the key role of the mentor/coach is to help the mentee use this untapped resourcefulness.

The National Health Service is currently undergoing a major cultural shift with the emergence of foundation trusts, performance management and a plurality of service providers. Trusts need to ensure good recruitment and retention of medical staff and reduce locum costs. Psychiatry too is changing - the advent of New Ways of Working, payment by results and the fact that psychiatrists nowadays may have less leverage within trusts, create new challenges for the specialty. Shorter specialist training periods place new pressures on trainees and consultants. This is taking place alongside high expectations from the government and the public. Consultants need to be adaptable and to have sound methods to facilitate their professiona and personal development. Achieving an optimal work-life balance is increasingly important. There is a growing evidence base on the usefulness of mentoring to both individuals and organisations. Since 2002, the College has recommended that all newly appointed consultants be offered a mentor, but a recent survey of mental health trusts conducted by the College (summarised in an appendix to this report) shows patchy implementation of this recommendation. A key aim of this guide is to highlight the usefulness of mentoring to all grades of psychiatrists at different stages in their careers. We hope mentoring will become a 'normal' widespread activity accessible to all psychiatrists.

doi: 10.1192/pb.bp.108.024471

\section{corrections}

Authors of the paper 'Pharmacological management of alcohol withdrawal in a general hospital' (Psychiatric Bulletin, 32, 452-454) are Siobhain Quinn, Rani Samuel, Jim Bolton, Anna Stout and
Borislav lankov. Borislav lankov is ST5 in General Adult Psychiatry, Weller Wing, Bedford Hospital, Bedford. The email for Siobhain Quinn is saquinn@ hotmail.co.uk.
'One man's trash is another man's treasure' (A pennyworth of history. Psychiatric Bulletin, 32, 479).

doi: 10.1192/pb.33.2.77 